\title{
ÉTICA CORPORATIVA: O USO DE MAPAS MENTAIS PARA O EXERCÍCIO DA A RESPONSABILIDADE CORPORATIVA
}

\author{
Luciane Alves Vieira ${ }^{1}$ \\ Marcelle Rossi Brandão ${ }^{2}$ \\ Universidade Santa Úrsula - USU \\ Ana Carolina de Gouvêa Dantas Motta ${ }^{3}$ \\ Universidade Santa Úrsula - USU
}

\begin{abstract}
Resumo
O mapeamento de conduta de profissionais tem sido uma tendência cada vez mais crescente entre as empresas, no intuito de evitar possíveis desvios. A fim de mitigar as não conformidades e verificar a eficácia no mapeamento das ações do comportamento direcionado as empresas têm desenvolvido ferramentas de processos para prevenir, reconhecer e corrigir estes desvios. Todo esse processo pode não estar sendo assimilado pelos profissionais em sua totalidade, pois a cada nova não conformidade referente à conduta ética destes, as empresas procuram as possíveis causas e buscam novas metodologias para tentar corrigi-las. Os mapas cognitivos podem ser considerados ferramentas estratégicas nos estudos comportamentais. A proposta de utilização de mapa cognitivo durante treinamentos e conhecimento dos Códigos de Ética nas empresas podem levar os funcionários a um maior nível de entendimento, participação e colaboração aprimorando assim a eficácia dos mesmos.
\end{abstract}

Palavras-chave: Mapa Cognitivo. Código de Ética. Empresa.

\section{CORPORATE ETHICS: THE USE OF MENTAL MAPS FOR THE EXERCISE OF CORPORATE RESPONSIBILITY}

\begin{abstract}
The mapping of professional conduct has been an increasing tendency among companies, in order to avoid possible deviations. In order to mitigate nonconformities and verify the effectiveness in mapping the actions of directed behavior, companies have developed process tools to prevent, recognize and correct these deviations. All this process may not be assimilated by the professionals in their totality, because with each new non-conformity referring to their ethical conduct, companies look for possible causes and seek new methodologies to try to correct them. Cognitive maps can be considered strategic tools in behavioral studies. The proposal of using a cognitive map during training and knowledge of the Codes of Ethics in companies can lead employees to a higher level of understanding, participation and collaboration, thus improving their effectiveness.
\end{abstract}

Keywords: Cognitive Map. Code of ethics. Business.

\footnotetext{
${ }^{1}$ Mestrado Profissional em Gestão do Trabalho para qualidade do ambiente construido, na Universidade Santa Ursula, iniciado em 2018 Possui graduação em Engenharia Mecânica pela Universidade Santa Úrsula. Tem experiência na área de Engenharia Mecânica, com ênfase em Inspeção de Equipamentos. Possui graduação em Bacharel em Biblioteconomia pela Faculdade Integradas Teresa DÀvila.

2 Doutoranda em Educação pela Universidade Lusófona de Humanidades e Tecnologia (ULHT), Lisboa -

Portugal. Mestre em Engenharia de Produção com pesquisa e trabalho publicado sobre engajamento de stakeholders para desenvolvimento de estratégias ambientais (UFRN), Especialista em Gestão Estratégica de Pessoas (UFRN) com ênfase no desenvolvimento da cultura organizacional e Bacharel em Administração (UnP). ${ }^{3}$ Graduada em Administração de Empresas pela PUC-Rio (2000), fez Mestrado em Administração e Ciências Contábeis na FACC (2006) e Doutorado em Engenharia de Produção na COPPE (2014), ambos na Universidade Federal do Rio de Janeiro.
}

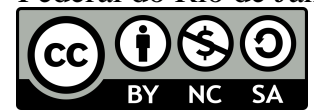




\section{INTRODUÇÃO}

As Legislações vigentes e os Códigos de Ética definem a ação comportamental esperada no desenvolvimento de atividades profissionais não sendo permitidos desvios destas. Podemos considerar o Código de Ética como uma forma de detalhar as ações comportamentais tornando notórios os itens que decorrem de maior atenção como forma de desenvolver as atividades com dedicação, honestidade, preocupação e atendendo os preceitos legais tendo como base os princípios da empresa.

Nas empresas o desenvolvimento de programas e ferramentas para combate a corrupção e a aplicação de códigos de Ética estão sendo aprimorados devido a aplicabilidade de Leis que dispõe sobre responsabilidade civil, administrativa pública e privada entre outras.

Este trabalho baseou-se numa pesquisa exploratória a fim de identificar a relevância da utilização de mapa cognitivo pelas empresas no treinamento dos códigos de ética.

O termo "Ética" foi analisado, bem como sua aplicação na área da psicologia considerando a moral como base, o conceito de mapas cognitivos e sua interpretação segundo as autoras na área da psicologia, como também foram analisados os códigos de ética de três empresas. Com a análise destes códigos foram mapeados alguns conceitos, pontos em comum, para dar base ao esquema desenvolvido. Para desenvolvimento dos mapas cognitivos, foi utilizado o software XMIND6.

\section{2 ÉTICA}

Ética, vem do grego ethos e significa caráter, comportamento. As reflexões sobre esse tema começaram na antiguidade, ocasião em que os filósofos mais notáveis, como Demócrito e Aristóteles, discutiam sobre a ética. O estudo da ética não é só explorado pela filosofia, mas por diversas áreas do conhecimento.

A ética é construída ao longo da história sustentada por valores morais determinados pela sociedade; ela se aproxima muito da moral em sua etimologia.

A moral pode ser considerada como a consciência do indivíduo, quando este começa a viver em sociedade e todo o seu aprendizado são as regras impostas pelo meio a fim de manter uma harmonia no convívio entre os indivíduos, o ideal para a conduta do indivíduo, porem considerando o bem-estar social. A moral tem evoluído com o passar do tempo devido as mudanças dos cenários e tem também garantindo o seu estudo nas diversas áreas do 
conhecimento, orienta o indivíduo sobre o que é justo e correto e o que deveria atribuir a seus valores em relação a sociedade, visando o bem comum.

As mudanças no novo cenário são responsáveis por esta requisição, lutar contra as injustiças que ferem a ética e a dignidade são dever de todo cidadão, agir, sobretudo com respeito, solidariedade, comprometimento pelo desenvolvimento do país, responsabilidade, dentre outros valores, não somente devem estar dentro de casa, mas também nas escolas, nos ambientes profissionais, nas ruas, em todo lugar.

Este trabalho abrange alguns conceitos de moral verificados na área de psicologia, segundo Yves de Taille (2006), existiram vários estudos que nortearam a Psicologia Moral até as novas abordagens teóricas conhecidas como personalidade ética.

A identificação de comportamento ético e moral dos indivíduos tendo como base os seus valores morais, considerando o sentimento de dever através de sua vida com a sociedade quanto maior for a interação desta vivência, maior sua motivação.

Faz-se necessário o conhecimento do conceito de ética para mensurarmos o comportamento moral, a análise feita por Taille (2006) dos trabalhos de alguns pesquisadores mostra-nos que sob os diversos pontos de vista destes, a Moral em suas variadas definições chega a um ponto de divergência, o sentimento de obrigatoriedade mensurado nas regras propostas pela sociedade.

No entanto, existem outros pontos que podem ser considerados, tais como a obrigação de ajudar ao próximo, mesmo não sendo imposto pela sociedade. Atos de sacrifícios próprios refletem uma cultura vinda da educação e outras vertentes, todavia deve-se considerar também as ações de obrigação sendo atendidas devido ao medo da punição, e não pela espontaneidade.

Podemos fazer uma análise de nossa situação atual na degradação da imagem dos indivíduos que fazem parte da sociedade, analisando suas ações e condutas. Tem-se que a noção de moral está parcialmente destruída por alguns e totalmente dilacerada por outros, a necessidade de considerar apenas o individualismo, se mantendo longe da obrigação e do dever.

Considerando moral como um respeito recíproco entre indivíduos de igualdade e justiça num plano universal, isso dentro de um cenário de crescimento e aprendizado do indivíduo para alimentar e fortalecer os seus valores morais.

Tailler (2006), com base nas abordagens de Piaget e Kohlgerg, compreendeu que o plano moral é estimulado pelos deveres e reciprocidade no desenvolvimento dos processos psicológicos, porém tece a seguinte consideração: “é possível prever a ação de um indivíduo de acordo com o que os outros consideram moralmente correto?" A forma como Tailler nos 
apresenta as relações entre juízo e ação; ação saber e querer ficou simplificada e de fácil entendimento.

Notando-se uma nova linha de lógica nos foi apresentado Durkheim que considera a sociedade como foco principal representante da massa que manifesta e decide o que é moralmente correto para cada indivíduo de forma repressiva através de uma pressão social.

Não serão detalhados os termos utilizados na psicologia, apenas as abordagens para mensurar a ideia principal da moral em alguns aspectos da necessidade de identificação de ações dos indivíduos e suas raízes afetivas que poderá ser estudado na abrangência da cognição, segundo Kant (1994).

Esse entrelaçar de ideias e conceitos mantém a moral muito próxima do significado da ética, ora verificados em vários dicionários como conjunto de regras para um indivíduo estabelecidos pela sociedade, porém ambos os conceitos podem atentar para os termos deveres e princípios. Normalmente o conceito de Ética é voltado para empresa e ordem públicas, ambos com o sentido de dever que exigem um comportamento moral.

A hierarquia de valores associados ao indivíduo, pode fazer com que este ocasionalmente tenha ações diferentes do esperado como dever e moral, estes valores podem ser de maior ou menor intensidades. Neste caso a ética deve sobrepor-se a moral.

Na análise de Pelloso e Ferraz (2005), a Moral seria a parte instituída para uma quebra de vinculo numa nova situação, todavia um vir a ser sempre constante.

\section{1 ÉTICA EMPRESARIAL E OS CÓDIGOS DE ETICA}

Vários são os problemas morais que atingem os indivíduos nos nossos dias, pois o egoísmo e os valores materiais veem se sobrepondo, a solidariedade vem tornando-se uma palavra pouco utilizada no cotidiano é necessário resgatar os valores morais e coletivos. Os Códigos de Ética visam preservar a sociedade, criados pelas corporações, abrangem diversos profissionais preservando seus valores morais e o ambiente que os cercam, e detalham os princípios destas.

A ética empresarial reflete se sobre os valores da companhia não só visando sua economia como também suas obrigações junto a sociedade propondo a integração junto visando o bem-estar de todos. (MONTEIRO; ESPIRITO SANTO; BONACINA, 2005).

As empresas tendem a ser transparentes nas orientações de seus membros através da implantação de seus códigos de ética onde detalham os normas de comportamento esperados. (SROUR, 2000). 
A implantação do Código de Ética nas Empresas reflete o respeito pela diferença entre os indivíduos e seus padrões de valores e a responsabilidade social, não deixando de englobar a segurança, meio ambiente, saúde entre outros aspectos na administração empresarial, estreitando assim os laços nas relações entre empregador, empregador e sociedade.

Conforme descrito por Martins e Leal (c2009), a ética orienta as ações e decisões do dever, como também a estratégia na tomada de decisão, o que devo fazer e como, a eficiência e eficácia da Empresa não são mais relevantes do que seu código de ética.

O comportamento direcionado dos profissionais deverá estar descrito e ser disponibilizado para consulta e treinamento dos profissionais, tendo como objetivo sua divulgação e conhecimento este por sua vez é conhecido no âmbito administrativo como Código de Ética.

O desenvolvimento do Guia tende a tangenciar as ações comportamentais dos profissionais com objetivos e interesses da empresa, utilizando-se de procedimentos internos e externos adaptados com a visão estratégica empresarial no intuito de estabelecer regras explicitas e coerentes dando credibilidade e transparência nos processos fundados na realidade da empresa.

Para eficácia da implantação do Código de Ética, toda empresa deverá estar comprometida com as normas desenvolvidas e sua manutenção, considerando medidas sancionais disciplinares para o seu descumprimento considerando também uma forma de recompensa pela disseminação e o atendimento deste por todas as áreas envolvidas. Sua implantação deve estar ligada diretamente a diretoria da empresa que deverá se fazer conhecer a todos os seus profissionais.

Os profissionais devem conhecer seus deveres e direitos e ajudar a moldar o melhor plano para que este guia seja claro e consiga mostrar a verdadeira identidade da empresa e suas atividades. Missão e compromissos assumidos com as partes envolvidas: desenvolvimento sustentável, desenvolvimento social, cultural e econômico do não só da empresa com também do meio.

A necessidade de verificação da eficácia da aplicação do guia se faz necessário e a possibilidade de colher informações direta ou indiretamente através dos canais de comunicação viabilizam esta verificação.

Existem ferramentas que possibilitam a auto avaliação dos sistemas para verificar a pratica e eficiência da aplicabilidade destes na Ética Empresarial mapeando os processos e propondo melhorias. 
Todo esse processo visa controlar as perdas financeiras, impunidades e garantir a credibilidade da empresa e tornando o processo de tomada de decisão confiável, transparente e seguro previsível do conforto no ambiente coorporativo

Condutas impostas visam valorizar os interesses da empresa perante a sociedade e sua força de trabalho mostrando os compromissos assumidos por esta em relação aos valores éticos e transparência no desenvolvimento dos negócios, onde qualquer situação de não conformidade são consideradas desvios operacionais inaceitáveis.

Os desvios de conduta são mapeados e estudados para a melhoria do processo de treinamento podendo-se utilizar várias ações e ferramentas para tornar o processo mais eficaz e efetivo. O conceito é prevenir o desvio conduzindo a conduta dos profissionais; detectar o desvio identificando os indícios e corrigir no sentido de tratar os desvios de forma coesa e transparente para atingir a eficiência do programa. Não conformidade são desvio que não podem ser tolerados.

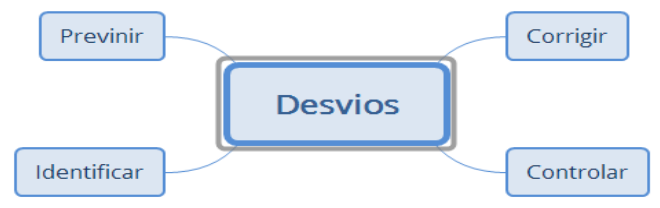

A Implantação de código de ética deve defini os princípios da Empresa de acordo com a pratica de ações rotineiras dos profissionais e o comprometimento destes, determinados pelo apoio da alta administração no desenvolvimento dos processos, acompanhamento de sua aplicação, verificação de sua eficácia e sendo forte nas tomadas de decisão durante as correções com uma visão estratégica.

A criação de uma cultura empresarial na implementação de programas de ética tende ao fortalecimento da imagem e reputação da companhia; criação de ambientes baseados na ética, integridade e transparência; na mitigação do risco de desvios de conduta; intensificar o gerenciamento do risco existente nos relacionamentos com terceiros; o aumento da competitividade entre outros.

É notório que a busca pela Ética nos negócios é almejada por todos que desejam fazer o certo e ter um ambiente melhor para trabalhar, num local harmonioso onde não existe a preocupação de violação de regulamentos de empresa e não há perda de recursos devido a sanções penais e fraudes denegrindo a imagem dos profissionais e da empresa, causando impacto direto nas negociações e destruindo a credibilidade da empresa.

Os processos desenvolvidos para implantação e aplicação dos códigos de ética tendem a diagnosticar aplicação dos códigos verificando a diversidade no mapeamento e tratamento 
dos desvios, no acompanhamento dos processos e procedimentos analisando os princípios da empresa e o estágio de desenvolvimento da política interna e sua gestão. Também atua no desenvolvimento de programas de conscientização dos profissionais no combate a corrupção.

Os processos almejam atingir a efetividade na integridade para consolidar a imagem da empresa perante o meio a fim de valorizar o ambiente e criar uma transparência em sua gestão fortalecendo a imagem da companhia; valorizando o ambiente; agindo conforme suas ações; definindo os princípios éticos e o código; atraindo investidores através de sua segurança e previsibilidade de ganhos;

Em concordância com o processo o Código de Ética deve mensurar as ações profissionais, como atender o que prevê o código de ética, sendo executados treinamentos efetivos, a distância ou presencial com orientação de profissional qualificados.

Marinho (1999) descreve a ética empresarial como a busca pelos valores onde os profissionais acreditam no processo e geram responsabilidade e integração destes, desde a alta administração até a comunidade, parte externas e interna acreditam nas consequências das ações tomadas. O código de Ética é a ferramenta utilizada para mensurar estes valores e vem se tornando mais aplicado e difundido no meio empresarial a nível mundial. (CARASCO; SINGH, 2003; CLEGG; KORNBERGER; RHODES, 2007).

O Código de Ética empresarial contempla os princípios, a missão da empresa, os direitos e deveres dos colaboradores no que se refere o exercício correto da profissão, seu relacionamento com os clientes, empregadores, com os colegas, com o meio ambiente, compromissos profissionais, com a ética e a rejeição de práticas ilegais, qualquer tipo de preconceito e assédio moral e sexual entre outros.

A aplicação do Código de Ética possibilita o fortalecimento da imagem da empresa junto a sociedade, aproximar os diversos profissionais da organização durante a elaboração do código ou do treinamento deste, tende a ser um instrumento para solucionar possíveis conflitos e problemas internos; auxilia na ordem e transparência pois proporciona mais coerência nas ações, transcreve a conduta moral da formação da empresa e a maneira que ela é conduzida; melhora da relação entre clientes, funcionários, fornecedores e até governo.

Grande parte dos conflitos nas empresas são de cunho moral gerados por assedio, discriminação, corrupção e outras ações que atingem de forma negativa os objetivos do Código de Ética, por isso quanto um indivíduo está em desacordo com o Código de Ética da empresa ele está passivo de punição que pode gerar uma pena de advertência verbal, o desligamento da empresa ou até a reclusão do mesmo dependendo da sua inflação. 
O Código de Ética empresarial contempla em sua maioria os princípios gerais de justiça e equidade; gestão da sustentabilidade; normas e padrões para o comportamento na empresa e de seus funcionários; penalizações com relação ao descumprimento do código; apresentação de um canal de denúncia.

Para uma eficácia na aplicação do código de ética é necessário o comprometimento de todos (qualquer processo só terá efetivação quando todos se conscientizarem e participarem), a elaboração de um processo para avaliação de riscos (um estudo e analise de históricos e potencias desvios devem ser mapeados, discutidos e eliminados para não se tornarem uma não conformidade em potencial, desenvolvendo ações preventivas) e um programa de treinamento e comunicação efetivo (um processo eficaz de divulgação e treinamento do comportamento direcionado sempre analisando o ponto de vista da gestão e educacional).

\subsection{EMPRESAS E SEUS CÓDIGOS}

Foram analisados os Códigos de Ética de três empresas localizados na Internet sem considerar parâmetros de porte ou tipo de Empresa com o intuito único de agrupar alguns itens e/ou assuntos dispostos nos mesmo que darão base ao desenvolvimento dos mapas cognitivos que servirão de suporte para este artigo.

Os códigos de Ética localizados na internet são referentes às Empresas abaixo informadas:

- $\quad$ PETRÓleo bRASileiRo S.A. (PETROBRÁS)

- $\quad$ STEMAC Energia S/A e STEMAC S/A Grupo Geradores

- Vale S.A.

Os dezesseis itens agrupados na tabela abaixo evidenciam a análise dos itens que aparecem nos três Códigos de Ética. Podemos a partir destes, destacar alguns que servirão de base para a aplicação do mapa cognitivo. 


\begin{tabular}{|c|c|c|c|c|}
\hline Item & Códigos de Ética & $\begin{array}{ll}\text { Petrobras } \\
\text { Empregado }\end{array}$ & $\begin{array}{l}\text { Stemac } \\
\text { Empregado }\end{array}$ & Vale / Empregado \\
\hline 1 & Responsabilidade Social & Identificado & Identificado & Identificado \\
\hline 2 & Responsabilidade Ambiental & Identificado & Identificado & Identificado \\
\hline 3 & Sustentabilidade de projetos & Identificado & Identificado & Identificado \\
\hline 4 & $\begin{array}{l}\text { Relações com o poder } \\
\text { público }\end{array}$ & Identificado & Identificado & Identificado \\
\hline 5 & $\begin{array}{l}\text { Transparência na } \\
\text { Comunicação com terceiros }\end{array}$ & Identificado & Identificado & Identificado \\
\hline 6 & $\begin{array}{l}\text { Manter Ouvidorias canais } \\
\text { formais }\end{array}$ & Identificado & Identificado & Identificado \\
\hline 7 & $\begin{array}{l}\text { Segurança e Saúde no } \\
\text { trabalho }\end{array}$ & Identificado & Identificado & Identificado \\
\hline 8 & $\begin{array}{l}\text { Combate a formas de } \\
\text { preconceito }\end{array}$ & Identificado & Identificado & Identificado \\
\hline 9 & $\begin{array}{l}\text { Situações conflitantes com } \\
\text { interesses da empresa }\end{array}$ & Identificado & Identificado & Identificado \\
\hline 10 & Sigilo de Informações & Identificado & Identificado & Identificado \\
\hline 11 & $\begin{array}{l}\text { Uso adequado dos bens } \\
\text { matérias }\end{array}$ & Identificado & Identificado & Identificado \\
\hline 12 & $\begin{array}{l}\text { Não obter vantagens } \\
\text { indevidas decorrente de } \\
\text { cargo }\end{array}$ & Identificado & Identificado & Identificado \\
\hline 13 & $\begin{array}{l}\text { Não exigir, aceitar ou } \\
\text { oferecer favor, doação, } \\
\text { vantagem para si ou para } \\
\text { qualquer outra pessoa }\end{array}$ & Identificado & Identificado & Identificado \\
\hline 14 & $\begin{array}{l}\text { Relacionamento com } \\
\text { Fornecedores }\end{array}$ & Identificado & Identificado & Identificado \\
\hline
\end{tabular}

No código da STEMAC Energia S/A e STEMAC S/A Grupo Geradores abaixo estão descritos partes do código onde há uma evidencia de relacionamento com os itens mapeados na tabela.

- Item 1 - "c) Responsabilidade Social.....seus colaboradores que compartilham o espírito de inclusão e justiça social e incentiva a adesão em programas, internos ou não, voltados para este propósito."

- Item 2 - "d) Responsabilidade Ambiental...Respeitar e preservar o meio ambiente, bem como estimular fornecedores, parceiros e prestadores de serviços a fazerem o mesmo, são objetivos importantes para atingir um desenvolvimento sustentável. "

- Item 3 - "Oferecer soluções em energia, com grupos geradores movidos pelos mais diversos combustíveis. Atuar com responsabilidade socioambiental, promovendo o crescimento e a realização profissional, financeira e pessoal de cada colaborador, garantindo retorno adequado aos acionistas." 
- Item 4 - ”e) Relação com o Poder Público...Qualquer forma de pressão ou solicitação consideradas fora de contexto por parte de agentes públicos devem ser refutadas e imediatamente comunicadas ao gestor responsável."

- Item 5 - "f) Relação com Acionistas e Investidores...Todos os colaboradores devem proteger os interesses dos acionistas e investidores. Deve ser assegurado o sigilo das informações que possam interferir na negociação de ações ou influenciar os movimentos de mercado, assim como decisões de investimento.

- Item 6 - "IX. Canais de Contato e Comitê de Conduta...a) Canais de Contato...b) Comitê de Conduta.....O grupo é responsável por tratar os casos a ele endereçados, verificar a validade do questionamento levantado, garantir a uniformidade dos critérios na resolução de casos. Também é atribuição do Comitê manter este documento atualizado conforme as diretrizes da Empresa e a legislação vigente.

- Item 7 - "b) Segurança e Saúde no Trabalho....Deve ser compromisso de cada um a busca pela prevenção de acidentes no ambiente de trabalho, bem como o relato para chefia imediata ou canais competentes em situações inseguras e de acidentes.

- Item 8 - "A STEMAC promove um ambiente onde seus profissionais estabeleçam relações com respeito e igualdade..... Nenhuma forma de discriminação é tolerável, seja por religião, raça, cor, nacionalidade, situação econômica, orientação sexual, deficiência, idade, estado civil ou por qualquer outra natureza.

- Item 9 - "VII. Conflito de Interesse. As relações, atividades e tomadas de decisão dos colaboradores da STEMAC devem ser estritamente profissionais e excluídas de qualquer conflito de interesse que prejudique a Empresa...O conflito de interesse surge quando há interferência de interesses pessoais em situações que possam influenciar as decisões profissionais da Empresa ou em relação a clientes, fornecedores, parceiros e concorrentes."

- Item 10 - "VI. Informações Confidenciais e Privilegiadas....a) Confidencialidade da Informação...b) Uso de Informação Privilegiada....c) Publicação de Dados....O sigilo de informações confidenciais sobre a Empresa e seus negócios deve ser rigorosamente respeitado. Apenas dados que foram publicados ou com a devida autorização prévia por representante legal podem ser utilizados para a publicação de artigos, trabalhos acadêmicos, palestras, seminários ou qualquer outro evento público.”

- Item 11 - "a) Utilização e Preservação de Bens...A utilização de serviços fornecidos pela Empresa, como internet e telefone, é recomendada para o uso profissional." 
- Item 12 - "Também não é admitido o uso de cargo ou função hierárquica superior para criar qualquer abuso de poder, constrangimento, ganho pessoal ao seu subordinado."

- Item 13 - "d) Presente, Entretenimento, Suborno...A oferta de benefício em troca de vantagem pode se caracterizar como uma ação de suborno, atitude não tolerada pela Empresa. "

- Item 14 - "b) Relação com Fornecedores...O colaborador deve tratar seus fornecedores e parceiros com ética e respeito. Assim como, buscar a qualidade dos produtos e serviços, associada ao equilíbrio nos custos."

\section{VALE}

- Item 1 - "1.13. Agir com responsabilidade social e com respeito à dignidade humana;"

- Item 2 - "1.12. Comprometer-se com o desenvolvimento sustentável das regiões onde a Vale atua e a obediência à legislação ambiental;"

- Item 3 - "A missão da Vale é transformar recursos naturais em prosperidade e desenvolvimento sustentável, visando ser a empresa de recursos naturais global $\mathrm{n}^{\circ} 1 \mathrm{em}$ criação"

- Item 4 - "2.8. Ofertar, pagar, prometer ou autorizar um benefício pessoal (seja pagamento ou qualquer outro tipo de benefício pessoal), direta ou indiretamente, a qualquer Funcionário de Governo;"

- Item 5 - "Observar práticas de boa governança corporativa, bons princípios e práticas contábeis e de gestão, comunicação clara, objetiva e tempestiva para seus acionistas, investidores e junto ao mercado de capitais"

- Item 6 - "Situações que caracterizem violação a este Código devem ser imediatamente comunicadas à Ouvidoria (disponível na intranet global da Vale ou no site www.vale.com). Serão observados os procedimentos que objetivem resguardar os direitos do denunciante e do denunciado, respeitando sempre a legislação local."

- Item 7 - "Respeito à vida, com uma atuação preventiva, cuidado com o bem-estar no trabalho, a saúde e a segurança das pessoas, instalações e processos do Sistema Vale, valorizando seus empregados"

- Item 8 - "2.2. Discriminação em função de etnia, origem, gênero, orientação sexual, crença religiosa, condição de sindicalização, convicção política, ideológica, classe social, condição de portador de deficiência, estado civil ou idade;" 
- Item 9 - "1.8. Evitar situação em que possa ocorrer conflito de interesses próprios com os interesses da Vale e, quando não for possível, abster-se de representar a Vale no assunto em questão, comunicando o fato imediatamente ao superior imediato;"

- Item 10 - "1.11. Evitar a divulgação de qualquer informação ou estratégia confidencial ou sensível da Vale a que tiver acesso, mesmo na condição de terceiro, inclusive se deixar de ter vínculo com a Vale, bem como manter confidencialidade sobre as informações privilegiadas da Vale;"

- Item 11 - "1.5. Preservar o patrimônio da Vale, incluindo a sua imagem e reputação, instalações, equipamentos e materiais, utilizando-os apenas para os fins a que se destinam;"

- Item 12 - "2.1. Uso do cargo visando obter vantagens pessoais, facilidades ou qualquer outra forma de favorecimento ou benefício pessoal ilegítimo, ou para terceiros de suas relações;"

- Item 13 - "2.6. Oferecer ou receber presentes em desacordo com as políticas e normas da Vale e como meio de exercer influência indevida, ou auferir ganho pessoal ou prêmio para si ou para terceiros;"

- Item 14 - "1.10. Não estabelecer relações comerciais com empresas ou indivíduos que não observem padrões éticos, de saúde e segurança e de direitos humanos compatíveis com os da Vale, bem como as práticas antissuborno e anticorrupção adotadas pela Vale;"

\section{Petrobras}

- Item 1 - "X. O Sistema Petrobras atua de maneira proativa em busca de níveis crescentes de competitividade, excelência e rentabilidade, com responsabilidade social e ambiental, contribuindo para o desenvolvimento sustentável do Brasil e dos países onde atua."

- Item 2 - 1.7 produzir Balanço Social e Ambiental anual com ampla participação interna, explicitando suas ações de promoção e desenvolvimento ambiental, social e cultural, assim como as consequências e impactos ambientais, sociais e culturais de suas atividades; "

- Item 3 - "6.6 investir na sustentabilidade de seus projetos, produtos e serviços, maximizando ....todo o ciclo de vida das suas instalações, operações e produtos; promover o uso sustentável de água,.... e da emissão de gases poluentes"; 
- Item 4 - "1.2 conduzir seus negócios com transparência e integridade, cultivando a credibilidade junto a seus acionistas, investidores, empregados, fornecedores, clientes, consumidores, poder público, imprensa, comunidades onde atua e sociedade em geral, buscando alcançar crescimento e rentabilidade com responsabilidade social e ambiental;"

- Item 5 - " 1.8 realizar uma comunicação transparente, verdadeira e correta, facilmente compreensível e acessível a todos os interessados, e uma publicidade fundada nos princípios estabelecidos neste Código de Ética;"

- Item 6 - "1.9 manter Ouvidorias como canais formais, entre outros, para recepção, encaminhamento e processamento de opiniões, sugestões, reclamações, críticas e denúncias sobre transgressões éticas, provenientes dos diversos públicos de relacionamento do Sistema, respeitando-se a legislação dos países onde atua; ”

- Item 7 - "2.1 promover condições de trabalho que propiciem o equilíbrio entre a vida profissional, pessoal e familiar de todos os empregados; 2.2 garantir segurança e saúde no trabalho, .... para isso todas as condições e equipamentos necessários; "

- Item 8 - "2.8 respeitar e promover a diversidade e combater todas as formas de preconceito e discriminação, por meio de política transparente de admissão, treinamento, promoção na carreira, ascensão a cargos e demissão; "

- Item 9 - "3.4 não se envolver em qualquer atividade que seja conflitante com os interesses do Sistema Petrobras e comunicar aos superiores hierárquicos ou às Ouvidorias qualquer situação que configure aparente ou potencial conflito de interesses;"

- Item 10 - “3.6 guardar sigilo das informações estratégicas e das relativas a atos ou fatos relevantes ainda não divulgados ao mercado, às quais tenham tido acesso, bem como zelar para que outros também o façam, exceto quando autorizados ou exigido por lei; ”

- Item 11 - " 3.7 assegurar o uso adequado do patrimônio material e imaterial do Sistema Petrobras, atendendo ao seu legítimo propósito, inclusive para preservar a imagem e reputação das empresas que o compõem e não utilizá-lo para obter qualquer tipo de vantagem pessoal";

- Item 12 - " 3.8 não obter vantagens indevidas decorrentes de função ou cargo que ocupam nas empresas do Sistema Petrobras";

- Item 13 - " 3.12 não exigir, nem insinuar, nem aceitar, nem oferecer qualquer tipo de favor, vantagem, benefício, doação, gratificação, para si ou para qualquer outra pessoa, 
como contrapartida a suas atividades profissionais, podendo aceitar ou oferecer brindes apenas promocionais, públicos, não exclusivos, sem valor comercial, nos seus relacionamentos com público externo ao Sistema;"

- Item 14 - " 4.3 selecionar e contratar fornecedores e prestadores de serviços baseandose em critérios estritamente legais e técnicos de qualidade, custo e pontualidade, e exigir um perfil ético em suas práticas de gestão e de responsabilidade social e ambiental, recusando práticas de concorrência desleal, trabalho infantil, trabalho forçado ou compulsório, e outras práticas contrárias aos princípios deste Código, inclusive na cadeia produtiva de tais fornecedores;"

\section{MAPA COGNITIVO}

Uma explanação básica para mapa cognitivo foi dada por Laszlo e colaboradores (1995) como sendo a representação do ambiente no cérebro pelo ser pensante onde há uma conexão entre os conceitos apresentados separadamente e entre si para que estes possam ser entendidos no ambiente proposto (LASZLO, et al., 1995).

Para elaboração do mapa cognitivo devem ser considerados não só o ambiente proposto ao indivíduo como também as experiências vivenciadas por este e a forma como são apresentados os conceitos. Os mapas tendem a ser construídos ou modificados conforme são conhecidos os conceitos e a forma como estes são apresentados aos indivíduos de acordo com a experiência vivida por estes deixando de ser apenas uma representação de sua percepção.

De acordo com a descrição de Bastos (2002) em Mapas cognitivos e a pesquisa organizacional; esta estruturação é denominada como linguagem modificada onde o ambiente físico é apenas parte da construção do mapa e a competência linguística seria o complemento desta estrutura tendo como base a experiência direta do indivíduo.

Devido à dinâmica das mudanças de cenário e conceitos, os mapas tendem a uma constante modificação, pois as informações recebidas variam de intensidade de acordo com a necessidade do indivíduo, suas experiências passadas e suas expectativas quanto ao futuro. Quanto maior a necessidade de novas informações pelo indivíduo, maior será a mudança estrutural dos mapas de forma contínua.

Os mapas apresentam de forma simplificada o ambiente de maneira imprecisa devido a dinâmica das mudanças, porém utilizam conceitos e padrões para sua construção.

Segundo Bougon (1983), os mapas cognitivos são constituídos por blocos e estes por ideias, já na interpretação de Swam (1997) os mapas cognitivos são representados por esquemas 
de modelos mentais desenvolvidos a partir da experiência do indivíduo e seu ambiente oferecendo a este uma visualização significativa identificada e resolução de problemas mostrando também as técnicas de mapeamento.

Conforme explanado por Laukkanen (1992) os mapas transcrevem partes verbais, orais ou escritos, que representam itens cognitivos, podendo ser utilizado como parâmetro de comparação, analise de estruturas conceituais individual ou em grupo.

Hoje os mapas cognitivos já estão sendo utilizados como técnicas metodológicas em grupos organizacionais para mapear estruturas de conhecimento nos processos.

Conforme descrito por Bastos (2002) a ideia de utilizar o mapa cognitivo como ferramenta para investigar processos organizacionais como dimensão simbólica e comunicativa, pode ser aplicada de acordo com a necessidade e os diferentes tipos de mapas.

Abaixo estão alguns dos diferentes tipos de mapas e uma breve explanação sobre os mesmos, conforme informou Fiol e Huff (1992)

O mapa de identidade, seria o primeiro mapeamento, a identificação dos conceitos "o que o indivíduo conhece sobre o conceito" é o sentido geral e podem estar inseridos nos demais mapas, a utilização dos conceitos e seus agrupamentos, vão dar insumo a estrutura do mapa que pode divergir da justaposição de conceitos, onde um indivíduo pode se contradizer ou mudar sua prioridade em relação as conexões apresentadas.

Os mapas de identidade abrangem estruturas cognitivas complexas se analisados os esquemas que são entendidos como estruturas subjacentes com uma vasta linha de interpretação com vária associações e conceitos articulados. Estes mapas são estruturados basicamente através de entrevistas ou estudos organizacionais, não possui um modelo fixo, porem depende da imaginação do seu desenvolvedor para agrupar os conceitos a fim montar uma estrutura significativas e que evidencie as informações de forma clara e objetiva.

Os mapas de categorização tendem a descrever como os indivíduos organizam ou estruturam o seu conhecimento, fundamenta-se nas lembranças organizadas da memória para desenvolver novos conceitos ou modificar os existentes uma evolução de aprendizagem.

Os mapas causais são utilizados em sua maioria nas organizações, pois servem como parâmetro para tomada de decisão conforme descrito por Laukkanen (1998) aplicado nas práticas gerenciais e coletivas.

Tem-se a coleta dos dados, identifica-se os conceitos, apresenta-se estes aos indivíduos que irão aplicar os seus conhecimentos e suas experiências, conceitos este mapeados no item 2.2 deste estudo. A partir destes conceitos inicia-se o desenvolvimento do mapa. 
A partir do desenvolvimento do mapa, tem-se um processo de aprendizado pessoal e coletivo, conforme descrito por Bastos (2002) através da reflexão do indivíduo na aplicação de sua experiência e conhecimento. Com a categorização dos conceitos e mantendo a linguagem natural é possível desenvolver os mapas de identidade que possuem metodologias especificas.

Porém quando se tem interatividade, o produto final pode ser bem diferente do esperado quando se deixa essa elaboração aberta, quando se oferece ao indivíduo a condição de desenvolver e não de escolhas limitadas.

Quando se oferece essa liberdade de desenvolvimento ao indivíduo, pode-se verificar a diferencia de conhecimento e entendimento de cada indivíduo e quando este conhecimento é transportado para o coletivo, como explicitado por Weick (1993), este mapeamento pode ser intangível porem conectada e desenvolvida por outros indivíduos.

Abaixo temos mapeado um desdobramento de ideias relacionadas a Ética alguns segmentos.

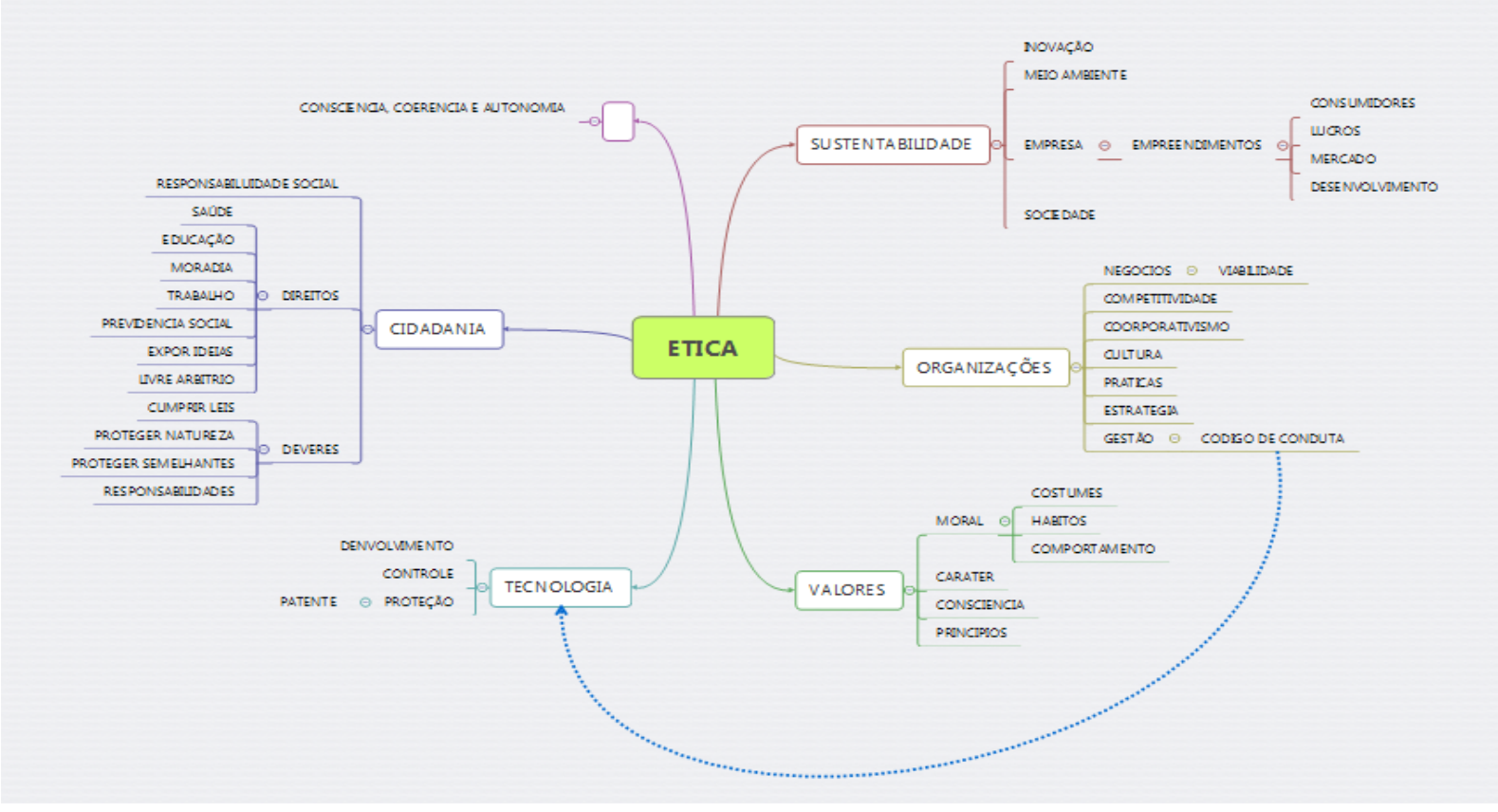

\section{APLICAÇÃO DO MAPA COGNITIVO NOS TREINAMENTOS DOS CÓDIGOS DE ÉTICA E COMPORTAMENTO}

A coleta dos dados foi desenvolvida através do estudo dos três Códigos de Ética informados no item 2.2 Empresas e seus códigos, podemos considerar este mapeamento como seleção de conceitos.

Foram identificados conceitos correlatos nos Códigos analisados, para elaboração do modelo do mapa cognitivo e para este modelamento foi utilizada a ferramenta XMaind 6, onde 
foram dispostos os conceitos, procurando manter uma hierarquia no desenho do diagrama e seus relacionamentos, possibilitando assim uma visão ampla generalizada deste modelo.

A forma mais conhecida e desenvolvida nas empresas é o processo de mapeamento livre individual, para determinar o nível de conhecimento do conceito proposto e a partir destes resultados verificar a melhor combinação representativa do Código de Ética para um mapeamento direcionado.

Neste mapeamento direcionado a proposta seria apresentar ao indivíduo alguns conceitos, elementos e parâmetros para que o mapa cognitivo a ser desenvolvido esteja alinhado com os princípios e valores da empresa.

Propondo um conceito geral de dois parâmetros considerados positivos e um negativo para a escolha do indivíduo, a escolha de parâmetros diferentes do proposto pelo Código de Conduta considerado negativo, este seja desenhado em vermelho para chamar atenção e abrir uma janela para explanação do porque aquele parâmetro estaria divergente da visão da empresa.

Da escolha do indivíduo pelo parâmetro de acordo com o Código de Ética este seria representado na cor azul com uma breve explanação e apresentação do item deste. Os parâmetros referentes ao conceito proposto devem ser apresentados ao indivíduo para escolha em tempo simultâneo. Para que este conheça todas as oportunidades de escolha e os parâmetros positivos podem ser contabilizados para evidenciar a eficácia do treinamento, um modelo informativo está apresentado no Apêndice I deste trabalho.

\section{CONCLUSÃO}

A utilização de mapas cognitivos utilizados como ferramenta no treinamento do Código de Ética das Empresas propõe um conceito de aprendizagem onde o indivíduo pode ou não interagir com o processo de desenvolvimento destes e pode ser aplicado entre indivíduos ou grupos de determinadas áreas afins.

A proposta é a criação de um cenário onde os indivíduos possam transcrever para estes esquemas as suas experiências e o seu conhecimento, considerando que a área de aplicação destes mapas está em constante modificação, o mapeamento do processo para desenvolvimento das ações de comportamento direcionado deverá ser analisada constantemente, pois existem mutações nas diversas épocas e os avanços tem que ser acompanhados

Porem deve-se verificar que por mais diferenças que hajam entre os indivíduos sobre suas experiências e conceitos, um dos pontos principais deste mapeamento e mostrar claramente aos indivíduos os princípios e valores da empresa durante a representação dos esquemas 
desenvolvendo estruturas que possam ajudar na compreensão das decisões e ações que os configuram.

Hoje é possível analisar uma série de técnicas utilizadas e discutidas por diversos autores da área para desenvolvimento dos mapas, para tanto a empresa pode verificar qual a técnica mais viável para aplicação do seu processo estrutural, considerando as diversas adversidades desta.

O treinamento dos Códigos de Ética das empresas visa o alcance da eficiência e o comprometimento de seus funcionários e sua direção na estabilidade e continuidade da finalidade proposta pelo neste, o engajamento e conhecimento pelos diversos colaboradores, clientes, fornecedores e parceiros, viabilizam esta atuação pois propagam o estreitamento dos propósitos no combate aos desvios.

Não se pode falar de ética empresarial sem falar de corrupção, quanto maior for o comprometimento das empresas no treinamento do Código de Ética maior será sua eficácia e menor será o risco de envolvimento em escândalos. 


\section{REFERÊNCIAS}

ARISTÓTELES. A política. 3. Ed. São Paulo: Athena, s/d.

. Ética a Nicômano. São Paulo: Abril, 1973. (Os pensadores, n.4.)

BASTOS, Antonio Virgílio Bittencourt. Mapas cognitivos e a pesquisa organizacional: explorando aspectos metodológicos. Estudos de Psicologia 2002.

BOUGON, M.. Uncovering cognitive maps: The Self-Q Technique. In MORGAN, G. (Org.), Beyond method. Newbury Park: Sage, 1983, p.160-72.

CARASCO, E. F.; SINGH, J. B. The content and focus of the codes of ethics of the world's largest transnational corporations. Business and Society Review. USA and UK: Blackwell Publishing, v.1, n.108, p.71-94, mar. 2003.

CLEGG, S.; KORNBERGER, M.; RHODES C. Business ethics as practice. British Journal of Management. USA and UK: Blackwell Publishing, v. 18, n. 2, p. 107, jun. 2007.

COMPANHIA VALE DO RIO DOCE S. A. (CVRD). Disponível em:

<http://www.cvrd.com.br>. Acesso em: 10 abr. 2007.

FIOL, C. M.; HUFF, A. Maps for managers: where are we? Where we go from here? Journal of Management Studies, v. 29, n. 3, 267-85, 1992.

KANT, E. Métaphysique des moeurs, première partie. Paris: Flamarion, 1994.

LASZLO, E., et al. The evolution of cognitive maps - new paradigms for the twenty-first century. Amsterdam: Gordon and Breach, 1995.

LAUKKANEN, M. Comparative cause mapping of management cognitions. Helsinki: Helsinki School of Economics, 1992.

LAUKKANEN, M. Conducting causal mapping research: opportunities and challenges. In EDEN, C.; SPENDER, J.-C. (Orgs.). Managerial and organizational cognitons - theory, methods and research. London: Sage, 1998, p.168-191.

MARINHO, L. H. L. Controle Gerencial: padrões de conduta ética nos negócios em uma empresa multinacional - um estudo de caso. 1999. 134 p. Dissertação (Mestrado em Administração) - Instituto de Pós Graduação e Pesquisa em Administração - COPPEAD, Universidade Federal do Rio de Janeiro, Rio de Janeiro, 1999.

MARTINS, Jefferson Carlos; LEAL, Manoel Flávio. Ética e relações pessoais no ambiente de trabalho. Bate byte, c2009. Disponível em:

<http://www.batebyte.pr.gov.br/modules/conteudo/conteudo.php?conteudo=1039>. Acesso em: 20 mar. 2018.

MONTEIRO, J. K.; ESPIRITO SANTO, F. C. do; BONACINA, F. Valores, ética e julgamento moral: um estudo exploratório em empresas familiares. Psicologia: Reflexão e Crítica. Porto Alegre: Curso de Pós-Graduação em Psicologia da Universidade Federal do Rio Grande do Sul, v.18, n.2, p.237-246, ago. 2005. 
PELLOSO, Rodrigo Gelamo; FERRAZ, Maria da Graça Chamma Ferraz e. Ética e moral como modos de produção de subjetividade. Trans/Form/Ação, São Paulo, 28(2): 117-128, 2005.

PETROBRAS. Site oficial da Petrobras. Disponível em:

$<$ http://sites.petrobras.com.br/minisite/petrobrasbiocombustivel/arquivos/Codigo $\% 20 \mathrm{de} \% 20 \mathrm{E}$ tica\%20do\%20Sistema\%20Petrobras.pdf $>$.

PIAGET, J. Etudes sociologiques. Paris: Droz, 1977.

SROUR, R. H. Ética empresarial: posturas responsáveis nos negócios, na política e nas relações pessoais. Rio de Janeiro: Campus. 2000.

TAILLE, Y. de. Moral e ética: dimensões intelectuais e afetivas. Porto Alegre: Artmed, 2006. 


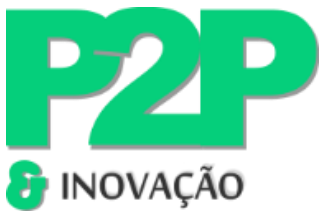

ARTIGO

APENDICE A

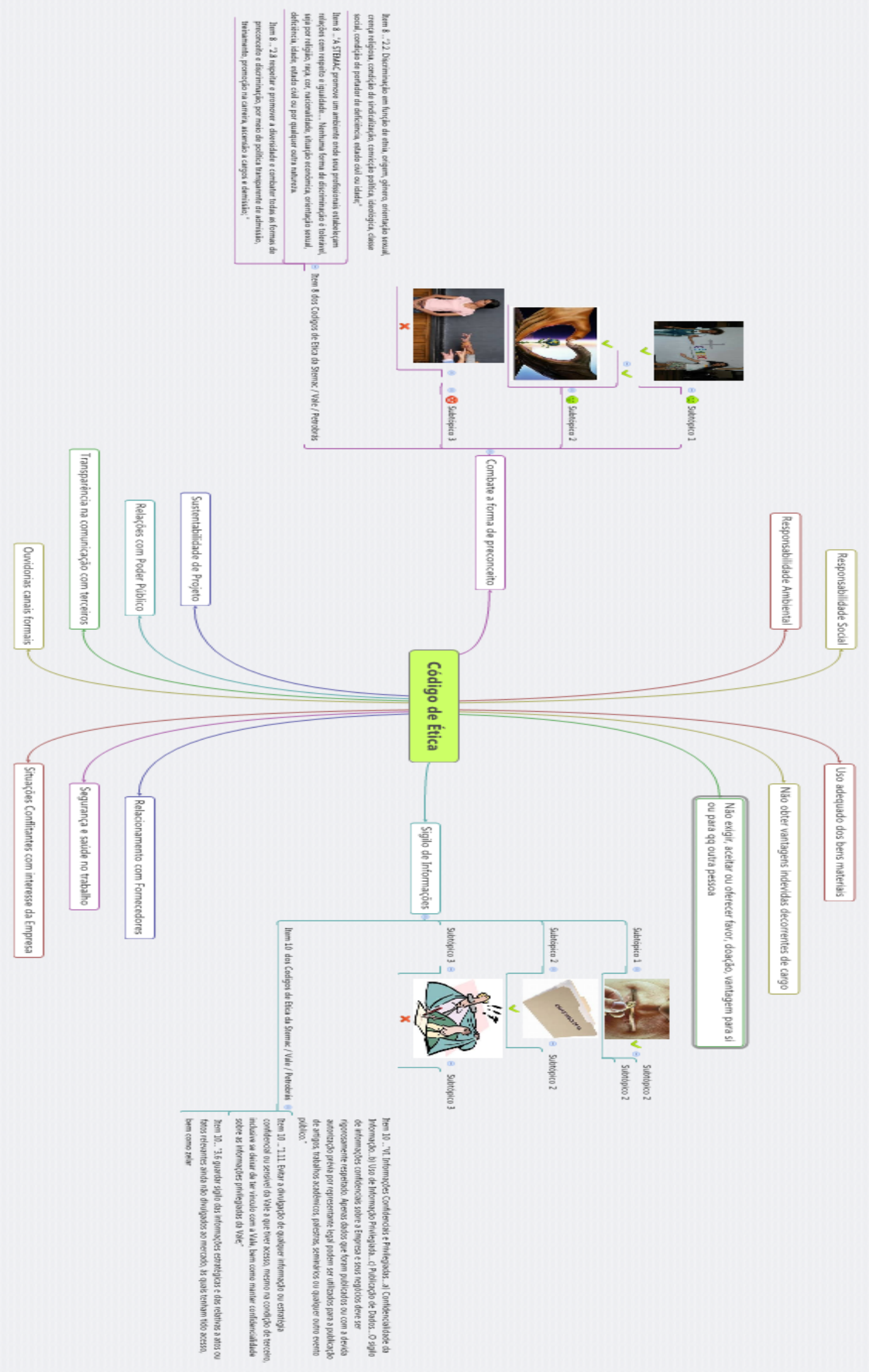

176

P2P \& INOVAÇÃO, Rio de Janeiro, v. 5 n. 1, p.156-176, Set./Fev. 2018. 